\title{
Effect of Substrate Ratios and the Species of Sugar on the Antioxidant Activity of Glycosylated Products of the Rana Debris Collagen Peptide
}

\author{
Naixin Kang,(The First Author), Hongxin Song ${ }^{1,(\text { The First Author), Wenyu Zhang }}{ }^{2}$, Jing Zhao ${ }^{1}$, Menghan Zhang ${ }^{1}$, Wenxin Xiong ${ }^{1}$, \\ Chunyu $\mathrm{Xi}^{1 *}$ \\ ${ }^{1}$ College of Food Science and Engineering, Jilin University, 130062 Changchun, China \\ ${ }^{2}$ College of China-Japan Friendship Hospital, Jilin University, 130062 Changchun, China
}

\begin{abstract}
The active peptide (molecular weight $<3500 \mathrm{Da}$ ) of the enzymatic hydrolysis from Rana debris is used as a raw material of glycosylation. The peptide can be affected by environmental factors, such as $\mathrm{pH}$ and temperature, which can destroy structural and functional properties, so the peptide is usually modified by glycosylation. To investigate the effects of glycosylation on the antioxidant activity of Rana Debris Collagen Peptide (RDCP), glycosylated compounds were prepared using different ratios of RDCP and xylose or glucose by the Maillard reaction. The results indicated that the peptide-xylose compound (PXC) showed higher antioxidant activity than the peptide-glucose compound (PGC), and RDCP and xylose heated at a ratio of 1:4 showed good antioxidant properties. The correlation between the glycosylation degree and antioxidant activity was strong. These results indicated that glycosylation can enhance the antioxidant activity of RDCP. Such glycosylated products can be used in the field of food research.
\end{abstract}

\section{Introduction}

Rana is a precious frog species for both food and medicine [1]. It has high nutritional value and is also called "pure green food". Rana debris, a by-product of Rana processing, includes Rana skin, Rana meat, and Rana bone. A peptide has been enzymatically hydrolyzed from the Rana debris for use in research. The structure and functional characteristics of this peptide are easily destroyed because it is susceptible to $\mathrm{pH}$ [2], temperature [3], and other environmental effects [4], which limits the industrial use of the peptide.

There has been substantial research into enhancement of the stability and biological properties of the peptide [5]. Glycosylation via the Maillard reaction is one of the most studied processes in food science [6]. This glycosylation, a type of chemical modification, occurs between the amino group of an amino acid, peptide, or protein and the carbonyl group of a reducing sugar [7]. Some studies have shown that glycosylation can improve the functional properties of proteins, including solubility, foaming properties, hydrophobicity, and emulsification $[7,8]$. In addition, Pui Khoon Hong's study suggested that glycosylation of fish gelatin peptides with glucosamine enhanced the bioactivity, including antioxidant and antimicrobial activity [9]. According to Hong Pui Khoon's study, glycosylation of gluten hydrolysates with glucose at mild temperatures enhanced antioxidant and antimicrobial properties [9]. Use of the Maillard reaction has also been shown to enhance the antioxidant activity of silver carp protein hydrolysate
[10]. However, the effects of glycosylation on the antioxidant activity of RDCP have not been investigated. Thus, it is important to study glycosylation involving RDCP in detail.

The objective of this study was to produce glycopeptides with different levels of glycosylation and to evaluate the effect of the type of monosaccharide and the mass ratio of the reactants on the degree of glycosylation between RDCP and either xylose or glucose. The antioxidant activity of the conjugated peptides was compared with the native peptide and the optimal mass ratio was determined.

\section{Materials and methods}

\subsection{Materials}

Rana debris collagen peptide was purchased from Jilin Fangping technology Co., Ltd., (Jilin, China). Common chemicals were purchased from different chemical reagent Co., Ltd. 2,2-diphenyl-1-picrylhydrazyl (DPPH) was purchased from Solarbio Co., Ltd. ( $\geq 97.0 \%$, China); xylose, glucose, tris-hydroxymethyl aminomethane and L-leucine were purchased from Shanghai Huishi Biochemical Reagent Co., Ltd. (biochemical reagents, China); Pyrogallol, sodium dodecyl sulfate $\beta$ mercaptoethanol and o-phthalaldehyde were purchased from Tianjin Guangfu Fine Chemical Research Institute (chemical reagent, China); sodium tetraborate were purchased from Shenyang Dongxing Reagent Co., Ltd.

\footnotetext{
* Corresponding author: Chunyu Xi, xichunyu@jlu.edu.cn
} 
(AR, China); hydrogen peroxide was purchased from Kaiyuan Chemical Reagent Factory (AR, China); sodium hydroxide, hydrochloric acid, anhydrous ethanol, sodium tetraborate, sodium dodecyl sulfate, ferrous sulfate, salicylic acid, sodium dihydrogen phosphate, disodium hydrogen phosphate, potassium ferricyanide, trichloroacetic acid, and ferric chloride were purchased from Beijing Chemical Factory (AR, China).

\subsection{Preparation of glycosylated complexes}

RDCP and xylose or glucose $(\mathrm{w} / \mathrm{w}=1 / 0,1 / 1,1 / 2,1 / 4$, $1 / 6$, and $1 / 8$ ) were dissolved in deionized water to a final concentration of $10 \mathrm{mg} / \mathrm{mL}$ and the $\mathrm{pH}$ was adjusted to 7 with $0.2 \mathrm{~mol} / \mathrm{L} \mathrm{NaOH}$. Then, the mixture was incubated at $60{ }^{\circ} \mathrm{C}$ for $24 \mathrm{~h}$. After incubation, the reactive solution was freeze-dried to obtain the glycosylated compounds $[11,12]$.

\subsection{Determination of intermediates and browning intensity}

The glycosylated products $(0.1 \mathrm{~g})$ were dissolved in distilled water $(10 \mathrm{~mL})$ and the absorbance was measured using a ultraviolet spectrophotometer at 294 and $420 \mathrm{~nm}$, for determination of intermediates and browning intensity, respectively.

\subsection{Determination of $\mathrm{pH}$}

The glycosylated products $(0.2 \mathrm{~g})$ were dissolved in distilled water $(20 \mathrm{~mL})$, and the $\mathrm{pH}$ values of the compounds were measured using a $\mathrm{pH}$ meter at room temperature.

\subsection{Determination of degree of graft}

Degree of graft is determined using the orthophthaldialdehyde (OPA) method described by Liu Fuguo and others (2015) [13] with slight modification. The OPA reagent was prepared: $0.04 \mathrm{~g}$ of OPA (dissolved in $1 \mathrm{~mL}$ of absolute ethanol), $25 \mathrm{~mL}$ of $0.1 \mathrm{~mol} / \mathrm{L}$ sodium borate buffer $(\mathrm{pH} 9.55), 100 \mu \mathrm{L}$ of $\beta$-mercaptoethanol, and $2.5 \mathrm{~mL}$ of $20 \%$ sodium dodecyl sulfate $(\mathrm{w} / \mathrm{v})$ were dissolved in distilled water. Then $4 \mathrm{~mL}$ of the OPA reagent and $200 \mu \mathrm{L}$ of the glycosylated compounds solution were mixed and reacted in a $35{ }^{\circ} \mathrm{C}$ water bath for $2 \mathrm{~min}$. The absorbance at $340 \mathrm{~nm}$ was measured using a spectrophotometer. The amount of free amino groups was calculated using the calibration curve of Lleucine as a standard. The degree of graft (DG) of the conjugates was calculated as follows:

$$
D G \%=\left(G_{0}-G_{l}\right) / G_{0} \times 100
$$

Where $G_{0}$ is the amount of free amino groups in the RDCP and $G_{1}$ is the amount of free amino groups in the conjugates.

\subsection{DPPH radical scavenging activity}

DPPH (0.002 g) was weighed accurately and dissolved in anhydrous ethanol $(50 \mathrm{~mL})$ to make a DPPH solution with a concentration of $0.1 \mathrm{mmol} / \mathrm{L}$. The glycosylated compounds (2 mL; $10 \mathrm{mg} / \mathrm{mL})$ and DPPH solution (2 $\mathrm{mL}$ ) were added to the same test tube and placed at room temperature in the dark for $30 \mathrm{~min}$, followed by measuring the absorbance at $517 \mathrm{~nm}$ to give $A_{1}$. The percentage of DPPH radical scavenging activity was calculated using the following equation:

$$
\begin{aligned}
& \text { DPPH radical scavenging rate } \%=\left\{1-\left[\left(A_{1}-A_{3}\right) / A_{2}\right]\right\} \\
& \times 100
\end{aligned}
$$

$A_{2}$ and $A_{3}$ were measured in the same manner, except that $2 \mathrm{~mL}$ of anhydrous ethanol was used instead of the sample and DPPH solutions, respectively.

\subsection{Hydroxyl radical (-OH) scavenging activity}

The hydroxyl radical scavenging rate of the PXC and PGC were determined by the method of Zhou Xiaoqiu (2012) [14]. First, $1 \mathrm{~mL}$ of glycosylated compounds solution $(10 \mathrm{mg} / \mathrm{mL})$ were mixed with $1 \mathrm{~mL}$ of FeSO4 solution $(9 \mathrm{mmol} / \mathrm{L}), 1 \mathrm{~mL}$ of salicylic acid-ethanol solution $(9 \mathrm{mmol} / \mathrm{L})$, and $1 \mathrm{~mL}$ of $\mathrm{H}_{2} \mathrm{O}_{2}$. Then the mixture was incubated at $37{ }^{\circ} \mathrm{C}$ for $30 \mathrm{~min}$ followed by centrifuging at $3000 \times \mathrm{g}$ for $5 \mathrm{~min}$. Finally, the absorbance was measured at $510 \mathrm{~nm}$. Distilled water (1 $\mathrm{mL}$ ) was used instead of the sample as a control, and the hydroxyl radical scavenging rate was calculated by the following equation:

\section{Hydroxyl radical scavenging rate $\%=\left[\left(A_{0}-A_{1}\right) / A_{0}\right] \times$ 100}

$\mathrm{A}_{0}$ : absorbance of the control; $\mathrm{A}_{1}$ : absorbance of the sample.

\subsection{Superoxide anion $\left(\mathrm{O}^{2-} \cdot\right)$ scavenging activity}

The superoxide anion scavenging rate of the PXC and PGC was determined by the method of Zhuang Yongliang (2011) [15]. First, $2 \mathrm{~mL}$ of Tris-HCl buffer solution $(50 \mathrm{~mL} / \mathrm{L})$ and $1 \mathrm{~mL}$ of glycosylated compounds solution $(10 \mathrm{mg} / \mathrm{mL})$ were added to a test tube and mixed with $0.5 \mathrm{~mL}$ of pyrogallic acid $(25$ $\mathrm{mmol} / \mathrm{L}$ ). Then, the mixture was incubated at $25{ }^{\circ} \mathrm{C}$ for $20 \mathrm{~min}$. Finally, the reaction was stopped by adding 50 $\mu \mathrm{L}$ of concentrated hydrochloric acid $(10 \mathrm{~mol} / \mathrm{L})$, followed by measuring the absorbance at $420 \mathrm{~nm}$. Distilled water $(1 \mathrm{ml})$ was used instead of the sample as a control, and the superoxide anion scavenging rate was calculated by the following equation:

Superoxide anion scavenging rate $\%=\left[1-\left(A_{2}-A_{1}\right) / A_{0}\right]$ $\times 100$

$\mathrm{A}_{0}$ : absorbance of the pyrogallol system without sample;

$\mathrm{A}_{1}$ : absorbance of the non-pyrogallol system with sample;

$\mathrm{A}_{2}$ : absorbance of the pyrogallol system with sample. Reducing power 
The reducing power of the PXC and PGC was determined by the method of You Juan. (2011) [10]. First, $1 \mathrm{~mL}$ of glycosylated compounds solution (10 $\mathrm{mg} / \mathrm{mL}$ ) were mixed with $2 \mathrm{~mL}$ of $0.2 \mathrm{~mol} / \mathrm{L}$ sodium phosphate buffer ( $\mathrm{pH}$ 6.6), and the reaction was initiated by adding potassium ferricyanide $(1 \%, w / v)$. The mixture was incubated at $55^{\circ} \mathrm{C}$ for $20 \mathrm{~min}$. Then, $2 \mathrm{~mL}$ of trichloroacetic acid $(10 \%, \mathrm{w} / \mathrm{v})$ was added and the mixture was centrifuged at $3000 \times \mathrm{g}$ for $10 \mathrm{~min}$. Finally, $2.5 \mathrm{~mL}$ of the supernatant liquid was mixed with $2 \mathrm{~mL}$ of distilled water and $0.5 \mathrm{~mL}$ of $\mathrm{FeCl}_{3}(0.1 \%$, w/v). After a 10 -min reaction time, the absorbance of the resultant solution was measured at $700 \mathrm{~nm}$. Distilled water $(1 \mathrm{~mL})$ was used instead of the sample as a control, and the percentage of reducing power was calculated by the following equation:

Reducing power = absorbance of sample group absorbance of control

\subsection{Statistical analysis}

Statistical analyses were conducted using the software package SPSS 19 (SPSS Inc., Chicago, USA). Mean values were considered significant when $\mathrm{P}<0.05$. Graphs were drawn with OriginPro 8.5 software (OriginLab Corporation, Northampton, MA, USA). Each experiment was performed in triplicate.

\section{Results and discussion}

\subsection{Determination of intermediates and browning intensity}

The Maillard reaction can be divided into three stages [7]: the initial stage, the intermediate stage, and the final stage. In the initial stage, the reaction of the reducing sugar and an amino acid causes the formation of a substance that has an ultraviolet absorption peak that can be detected at $294 \mathrm{~nm}$. The second stage generates macromolecular compounds. The final stage will generate black melanin, which can be detected at $420 \mathrm{~nm}$. Thus, A294 and A420 are typical indicators for the colorless intermediate compounds and final browning compounds, respectively.

The UV absorption and browning values of the glycosylated products of RDCP using different monosaccharides and different ratios of RDCP to the monosaccharides are shown in Figure 1. The intermediates and the degree of browning of the PXC increased with increasing ratios of xylose, while the absorbance of the PGC was almost the same as the RDCP. An increase in absorbance at $294 \mathrm{~nm}$ indicates the formation of a colored material and this substance may be a precursor material for the glycosylation reaction. The reason for the increase in absorbance at $420 \mathrm{~nm}$ may be that some of the intermediates polymerize to form a brown pigment. Matmaroh K [16] found that the degree of browning and the extent of the glycosylation increased with an increase in the concentration of the reactive substrate. Liu Fuguo [13] found that both the A294 and A420 values for lactoferrin significantly increased after conjugation with chlorogenic acid, and this was mainly because of the formation of protein-polyphenol covalent complexes. These results indicate that the A294 and A420 values of glycosylated products are a direct and easy indication of the progress of the Maillard reaction.

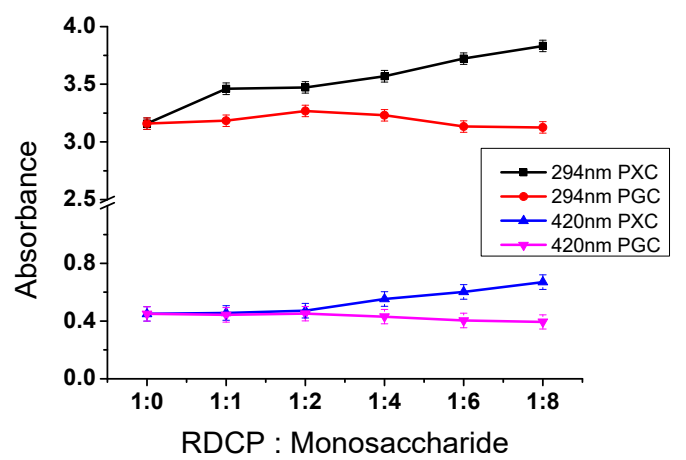

Fig. 1. Effect of the types of monosaccharides (xylose or glucose), and the ratios of RDCP to monosaccharide on A294 and A420 of the glycosylated products. A294 and A420 are typical indicators for the colorless intermediate compounds and final browning compounds, respectively

\subsection{Determination of $\mathrm{pH}$}

The initial $\mathrm{pH}$ of the reaction system will affect the glycosylation reaction. Therefore, the initial $\mathrm{pH}$ of each reaction system was adjusted to 7 with $0.2 \mathrm{~mol} / \mathrm{L} \mathrm{NaOH}$ and the $\mathrm{pH}$ was not further controlled during the reaction. According to Figure 2, the $\mathrm{pH}$ values of the glycosylated products can be observed to be significantly decreased comparing with the starting solution. Studies have shown that the process of glycosylation will involve some organic acid formation [13]. In addition, the amino groups of the peptide are consumed as the glycosylation proceeds so the $\mathrm{pH}$ value of the whole system decreases. Juan You showed that the $\mathrm{pH}$ value of the glycosylated products of silver carp protein hydrolyzate decreased and was the lowest when the ratio of hydrolyzate to glucose was 1:1 [10]. Marija Perusko [17] has shown that the final $\mathrm{pH}$ value of the glycosylated product of ultrasoundassisted whey protein was reduced and the results of the present study were consistent with their conclusions. Thus, the reduction in the final $\mathrm{pH}$ value of the glycosylated product is because of the production of acidic substances and the consumption of protein amino groups. 


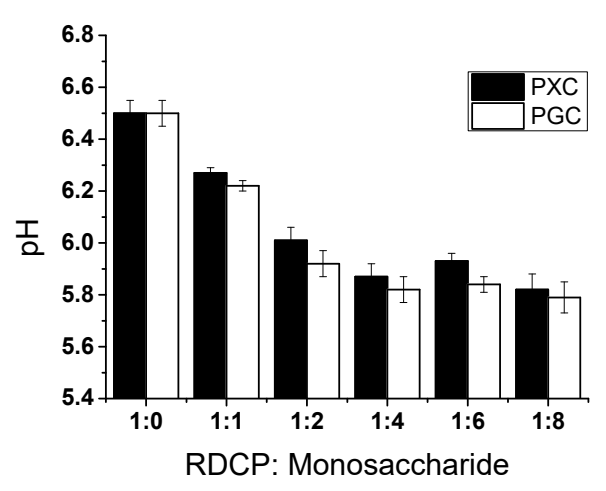

Fig. 2. Effect of the type of monosaccharide (xylose or glucose), and the ratios of RDCP to monosaccharide on the $\mathrm{pH}$ of the glycosylated products.

\subsection{Determination of degree of graft}

When assessing the formation of glycosylated compounds, evaluation of the degree of graft is critical to the degree of binding between peptide and sugar, and is often used to determine the progress of the Maillard reaction. In this study, the degree of graft was determined using the OPA method. Figure 3 shows the degree of graft of the glycosylated products. The degree of graft of the glycosylated compounds increased compared with RDCP, probably because of interactions between the amino acid and the reducing sugar or their degradated products in the Maillard reaction. The degree of graft showed an upward trend with an increase in the proportion of sugar, and this trend lessened at 1:6, indicating that the reaction had reached saturation. The degree of graft of chlorogenic acid-lactoferrin and glucose is up to $40.5 \%$, and the degree of graft of polydextrose is $11.72 \%$; hence, it is clear that protein glycosylation is more efficient with monosaccharides [13]. However, changes in free amino groups content after glycosylation were not obvious in other research [10]. The Maillard reaction occurs between the RDCP and the reducing sugar, this is mainly because the lysine, serine, threonine, and asparagine amino groups of the RDCP are all involved in the glycosylation. It is possible that steric hindrance in the peptide leads to incomplete reactions.

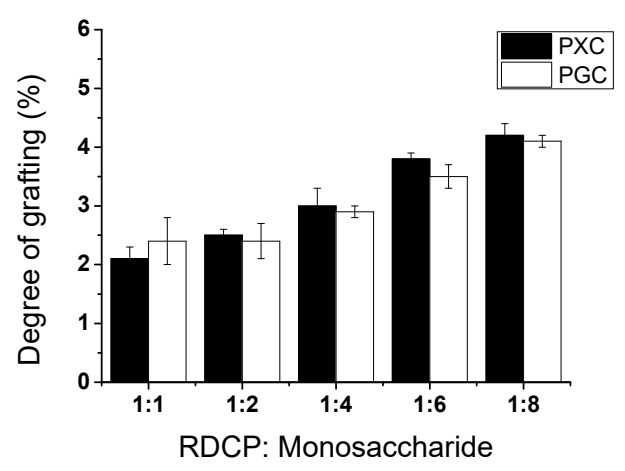

Fig. 3. Effect of the types of monosaccharides (xylose or glucose), and the ratios of RDCP to monosaccharide on the degree of graft of the glycosylated products.

\subsection{DPPH radical scavenging activity}

DPPH radicals dissolved in anhydrous ethanol are violet and have a strong absorbance at $517 \mathrm{~nm}$. When other free-radical scavengers are present, these pair with the DPPH single electrons, the absorption at $517 \mathrm{~nm}$ gradually disappears, and the solution turns from purple to yellow. Therefore, the DPPH radical scavenging activity is widely used to evaluate the antioxidant activity of peptides. The effect of changing the ratio of RDCP to monosaccharide on the DPPH radical scavenging activity was studied. Overall, the DPPH radical scavenging capacity of the PXC was better than the PGC (Figure 4a). When the ratio of RDCP to xylose was $1: 4$, the scavenging activity was the highest. The scavenging rate of the PXC and PGC increased compared with the RDCP.

Determining the DPPH radical scavenging ability of the samples was based on the combination of hydrogen atoms and electron transfer [18]. These activities may be mainly dependent on the sugar part of the glycopeptide, which can be either an electron donor or a receptor [19]. $\mathrm{Wu}$ Yalin [20] has shown that the antioxidant activity of glycopeptides isolated from Ganoderma lucidum depends on the carbohydrate moiety, and the peptide sequence was not important. In contrast, Rajapakse $\mathrm{N}$ [21] reported that aromatic amino acids had electron scavenging activity. In conclusion, the use of glucosamine for glycosylation may produce a product that enhances antioxidant capacity. You Juan [10] studied the effect of glycosylated complexes on the DPPH radical scavenging activity, the observed trend was consistent with the experimental results in the present research. In Sumaya-Martinez's study, the DPPH radical scavenging activity was the highest when the concentration was $50 \mathrm{mg} / \mathrm{mL}$. The results shown in Figure $4 \mathrm{a}$ indicate that glycosylation was an effective method to improve the DPPH radical scavenging activity of the peptide.
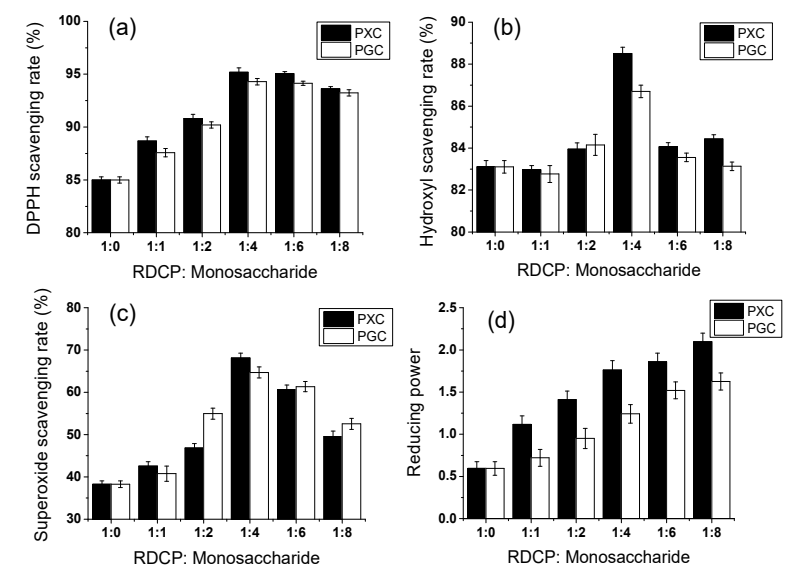

Fig. 4. Effect of the type of monosaccharide (xylose or glucose), and the ratios of RDCP to monosaccharide on (a) the DPPH radical scavenging activity, (b) hydroxyl radical scavenging activity, (c) superoxide anion scavenging activity, and (d) reducing power of glycosylated products. 


\subsection{Hydroxyl radical scavenging activity}

Living organisms constantly produce a variety of reactive oxygen species in the process of oxidative metabolism. Hydroxyl radicals are the most active reactive oxygen species in the body, and can directly or indirectly cause lipid peroxidation, protein denaturation, enzyme inactivation, DNA strand breaks, biofilm damage, and even organ failure and death. The sample solution shows a purple color when oxidized by hydroxyl radicals produced by Fenton's reaction, and conversely the oxidized solution is reduced to a colorless compound by antioxidants $[22,23]$. It can be seen from Figure $4 \mathrm{~b}$ that overall the scavenging activity of the PXC was significantly stronger than that of the PGC. The scavenging activity was highest when the ratio of RDCP to monosaccharide was $1: 4$, and the activity for other ratios was similar to the control group. Glycosylated products have a good hydroxyl radical scavenging capacity, mainly because they not only act as hydrogen donors, but are also $\mathrm{Fe}^{2+}$ chelators [24].

\subsection{Superoxide anion scavenging activity}

The generation and clearance of super oxide anions is in dynamic equilibrium in the normal body to prevent the accumulation of the anions in cells resulting in oxidation and tissue damage. Pyrogallol can rapidly oxidize and release oxygen ions in an alkaline environment, accompanied by the production of colored intermediates. The autoxidation of pyrogallol will be inhibited, and further accumulation of intermediates will be prevented, if antioxidant components are added to the system. Because such intermediates have a maximum absorbance at approximately $420 \mathrm{~nm}$, the oxidation of pyrogallol can be used to estimate the superoxide anion scavenging activity of a sample [25-27]. In Figure 4c, it can be seen that the superoxide anion scavenging activity of the PXC and PGC was significantly stronger than that of RDCP, and the scavenging activities of the PXC and PGC were similar to each other. The scavenging activity was the highest when the ratio of RDCP to xylose was 1:4. These results showed that glycosylation can enhance the superoxide anion scavenging activity of RDCP.

\subsection{Reducing power}

The reducing power of the PXC and PGC is based on the ability to provide electrons to form more stable products, and the reducing power can be determined by the ability of a peptide to reduce $\mathrm{Fe}^{3+}$ to form ferrous compounds. The potassium ferricyanide method is used for the determination of reducing power. The principle of this method is that the red trivalent iron compound oxidizes the sample, and is itself reduced to a yellow ferrous compound that can react with ferric ions to produce Prussian blue. The production of Prussian blue is directly dependent on the content of ferrous ions, but it is essentially determined by the antioxidant components reduced by potassium ferric chloride [28, 29]. Prussian blue has an absorption peak at $700 \mathrm{~nm}$, and the greater the absorbance at $700 \mathrm{~nm}$, the stronger the reducing power. As shown in Figure 4d, the reducing power of the complexes increased as the ratio of monosaccharide to RDCP increased, and this upward trend slightly lessened when the ratio of RDCP to monosaccharide was 1:6. Overall, the reducing power of the PXC was stronger than that of the PGC, and the reducing power after glycosylation was increased, which indicated that glycosylation can enhance the reducing power of the RDCP. The glucosamine rearrangement products thermally decompose to generate a substance having a reducing ability, and the advanced stage products of the Maillard reaction, such as hydroxyl ions and pyrrole, also have reducing activity. In addition, the reductones in the product can provide hydrogen atoms and react with peroxide precursors to prevent the formation of peroxides, and thus exhibiting reducing activity. The observed results for the reducing ability are consistent with the trends seen for changes in the intermediate products, browning degree, and degree of graft, which are consistent with previous results that found that there was a large correlation between the reducing ability and the degree of browning [30].

\subsection{Correlation analysis of the glycosylation degree and antioxidant activity}

Table 1 shows the correlation analysis of the glycosylation degree of xylose evaluated using the levels of intermediates, the degree of browning, the final $\mathrm{pH}$ value, the amount of free amino groups, the degree of graft, and the antioxidant activity of the products. The level of intermediates was strongly correlated with the degree of browning, the final $\mathrm{pH}$ value, the degree of graft, the DPPH radical scavenging activity, and the reducing power. The degree of browning was strongly correlated with the final $\mathrm{pH}$ value, the degree of graft, and the reducing power. The final $\mathrm{pH}$ value was correlated with the degree of graft, the DPPH radical scavenging activity, and the reducing power. The degree of graft was correlated with the DPPH radical scavenging activity and the reducing power. The DPPH radical scavenging activity was correlated with the superoxide anion scavenging activity and the reducing power. The hydroxyl radical scavenging activity was correlated with the superoxide anion scavenging activity.

Table 1. Correlation analysis of the glycosylation degree of xylose and the antioxidant activity.

\begin{tabular}{ccccccccc}
\hline & $\mathrm{A}_{294 \mathrm{~nm}}$ & $\mathrm{~A}_{420 \mathrm{~nm}}$ & Final $\mathrm{pH}$ & $\begin{array}{c}\text { degree of } \\
\text { graft }\end{array}$ & $\mathrm{DPPH}$ & $\mathrm{OH}$ & $\mathrm{O}^{2-}$ & $\begin{array}{c}\text { reducing } \\
\text { power }\end{array}$ \\
\hline $\mathrm{A}_{294 \mathrm{~nm}}$ & 1.000 & & & & & & \\
$\mathrm{~A}_{420 \mathrm{~nm}}$ & 0.900 & 1.000 & & & & & \\
Final pH & -0.901 & -0.801 & 1.000 & & & & \\
\hline
\end{tabular}




\begin{tabular}{ccccccccc}
\hline $\begin{array}{c}\text { degree of } \\
\text { graft }\end{array}$ & 0.997 & 0.890 & -0.915 & 1.000 & & & & \\
$\mathrm{DPPH}$ & 0.871 & 0.777 & -0.953 & 0.861 & 1.000 & & & \\
$\cdot \mathrm{OH}$ & 0.295 & 0.336 & -0.591 & 0.288 & 0.652 & 1.000 & & \\
$\mathrm{O}^{2-}$ & 0.575 & 0.544 & -0.757 & 0.550 & 0.893 & 0.845 & 1.000 & \\
$\begin{array}{c}\text { reducing } \\
\text { power }\end{array}$ & 0.970 & 0.894 & -0.975 & 0.972 & 0.945 & 0.487 & 0.711 & 1.000 \\
\hline
\end{tabular}

Table 2. Correlation analysis of the glycosylation degree of glucose and the antioxidant activity.

\begin{tabular}{|c|c|c|c|c|c|c|c|c|}
\hline & $\mathrm{A}_{294 \mathrm{~nm}}$ & $\mathrm{~A}_{420 \mathrm{~nm}}$ & Final $\mathrm{pH}$ & $\begin{array}{c}\text { degree of } \\
\text { graft }\end{array}$ & DPPH & $\cdot \mathrm{OH}$ & $\mathrm{O}^{2-\cdot}$ & $\begin{array}{c}\text { reducing } \\
\text { power }\end{array}$ \\
\hline $\mathrm{A}_{294 \mathrm{~nm}}$ & 1.000 & & & & & & & \\
\hline $\mathrm{A}_{420 \mathrm{~nm}}$ & 0.684 & 1.000 & & & & & & \\
\hline Final $\mathrm{pH}$ & -0.090 & 0.662 & 1.000 & & & & & \\
\hline $\begin{array}{l}\text { degree of } \\
\text { graft }\end{array}$ & -0.157 & -0.780 & -0.906 & 1.000 & & & & \\
\hline DPPH & -0.051 & -0.733 & -0.957 & 0.847 & 1.000 & & & \\
\hline$\cdot \mathrm{OH}$ & 0.573 & 0.076 & -0.462 & 0.162 & 0.534 & 1.000 & & \\
\hline $\mathrm{O}^{2-\cdot}$ & 0.224 & -0.468 & -0.885 & 0.637 & 0.930 & 0.726 & 1.000 & \\
\hline $\begin{array}{l}\text { reducing } \\
\text { power }\end{array}$ & -0.381 & -0.929 & -0.877 & 0.865 & 0.915 & 0.210 & 0.741 & 1.000 \\
\hline
\end{tabular}

This result is similar to the results of Manzocco L [31], who found that a correlation between antioxidant activity and browning was frequently observed during the Maillard reaction.

Table 2 shows the correlation analysis of the glycosylation degree of glucose and antioxidant activity. There were strong correlations between the degree of browning and reducing power. The final $\mathrm{pH}$ value was strongly correlated with the degree of graft, the DPPH radical scavenging activity, the superoxide anion scavenging activity, and the reducing power. The degree of graft was correlated with the DPPH radical scavenging activity and the reducing power. The DPPH radical scavenging activity was correlated with the superoxide anion scavenging activity and the reducing power. The correlation coefficient between the $\mathrm{pH}$ value and other factors for glucose is relatively strong, but the overall correlation coefficient is less than for xylose.

\section{Conclusion}

In this study, glycosylation through the Maillard reaction using xylose or glucose as the reducing sugar and controlling the mass ratio of the reactants was used to investigate the antioxidant activity of a peptide. The antioxidant properties of the peptide were improved after the glycosylation and these glycopeptides showed potential in antioxidant activity. The antioxidant activity of the PXC was higher than the PGC overall, and glycosylation of RDCP when the ratio of RDCP to xylose was 1:4 resulted in the highest antioxidant activity. There is potential for application of glycopeptides in food technology and this application may extend to other fields. The strategy adopted in this study shows promise for the production of new glycopeptides from Rana by-products.

\section{References}

1. EV Seliverstova, J Evol Biochem Physiol 48, 295305 (2012)

2. M Enciso, C Schuette, S Delle, Luigi, J Chem Phys, 143 (2015)

3. X Xu, X Xiao, S Xu, H Liu, Phys Chem Chem Phys, 18, 25465-25473 (2016)

4. AD Ozkan, AB Tekinay, MO Guler, ED Tekin, . RSC Adv, 6, 104201-104214 (2016)

5. Y Gao, JJ Li, L Zheng, Y Du, Protein Eng Des Sel, 30, 743-751 (2017)

6. LD Melton, Crit Rev Food Sci Nutr, 46, 337-350 (2006)

7. MS Martinez-Alvarenga, EY Martinez-Rodriguez, LE Garcia-Amezquita, GI Olivas, PB ZamudioFlores, CH Acosta-Muniz, DR Sepulveda, Food Hydrocoll, 38, 110-118 (2014)

8. R Horax, N Hettiarachchy, P Chen, J Food Sci, 79, C2215-C2221 (2015)

9. PK Hong, D Gottardi, M Ndagijimana, M Betti, Food Chem, 142, 285-293 (2014)

10. J You, Y Luo, H Shen, Y Song, Int J Food Sci Tech, 46, 2467-2474 (2011)

11. WJ Lin, HZ Liu, AM Shi, L Liu, Q Wang, B Adhikari, Int J Food Sci Tech, 52, 242-6253 (2015)

12. J Lazniewska, Y Rzhepetskyy, FX Zhang, GW Zamponi, N Weiss, Pflugers Arch, 468, 1837-1851 (2016)

13. F Liu, C Sun, D Wang, F Yuan, Y Gao, The Royal Society of Chemistry, 5, 78215-78228 (2015)

14. X Zhou, C Wang, A Jiang, Eur Food Res Technol, 234, 441-447 (2012) 
15. Y Zhuang, L Sun, J Food Sci, 76, C483-C489 (2011)

16. K Matmaroh, S Benjakul, M Tanaka, Food Chem, 98, 1-8 (2006)

17. M Perusko, A Al-Hanish, TC Velickovic, D StanicVucinic, Food Chem, 177, 248-257 (2015)

18. X Huang, Z Tu, H Xiao, H Wang, L Zhang, Q Zhang, P Niu, Food Res Int, 48, 866-872 (2012)

19. D Gottardi, PK Hong, M Ndagijimana, M , LWT Food Sci Technol, 57, 181-187 (2014)

20. Y Wu, D Wang, J Proteome Res, 8, 436-442 (2009)

21. N Rajapakse, E Mendis, WK Jung, JY Je, SK Kim, Food Res Inti, 38, 175-182 (2005)

22. DH Ngo, ZJ Qian, BM Ryu, JW Park, SK Kim, J Funct Foods, 2, 107-117 (2010)

23. S Sakanaka, Y Tachibana, N Ishihara, LR Juneja, J Agric Food Chem, 53, 464-468 (2005)

24. H Sun, S Jiang, M Zi, D Qi, Food Sci Biotechnol, 18, 1386-1391 (2009)

25. Y Zhang, Y Shen, H Zhang, L Wang, H Zhang, $H$ Qian, X Qi, Eur Food Res Technol, 224, 83-96 (2018)

26. B Sivaraman, RJ Shakila, G Jeyasekaran, D Sukumar, U Manimaran, G Sumathi, Food Sci Biotechnol, 25, 665-672 (2005)

27. M Du, L Zhao, C Li, G Zhao, X Hu, Eur Food Res Technol, 224, 659-665 (2007)

28. AJ Bedinghaus, HW Ockerman, J Food Sci, 60, 992-995 (1995)

29. TH Kwon, HJ Suh, IK Lee, BS Yun, TW Kim, DI Hwang, YJ Kim, MJ Kim, OO Kwon, CG Kim, Eur Food Res Technol, 237, 501-508 (2013)

30. D Huang, B Ou, RL Prior, J Agric Food Chem, 53, 1841-1856 (2005)

31. L Manzocco, S Calligaris, D Mastrocola, MC Nicoli, CR Lerici, Trends Food Sci Technol, 11, 340-346 (2000) 